\title{
Sistem Pakar Mendiagnosa Penyakit Ayam Kampung Menggunakan Metode Certainty Factor
}

\author{
${ }^{1}$ Sri Wahyuni, Paska Marto Hasugian ${ }^{2}$ \\ ${ }^{1,2}$ Teknik Informatika, STMIK Pelita Nusantara \\ Jl. Iskandar Muda No.1 Medan Baru \\ Email :1'wahyuniwhy234@gmail.com.2ㄹ. paskamarto86@gmail.com²
}

\begin{abstract}
Animal husbandry is the activity of breeding and raising livestock to obtain the benefits and results of these activities. Activities in the field of animal husbandry can be divided into two groups, namely livestock farming of large animals such as cows, buffaloes and horses, while the second group is farming of small animals such as chickens, ducks, birds and others. Village chicken farming activities have existed since ancient times. Village chickens start from the first generation, namely from the descendants of the red jungle fowl (Gallus gallus). Raising free-range chickens is not easy because there are many things that must be considered and must have problems, therefore an expert system is needed to assist farmers in diagnosing and knowing the type of disease and symptoms experienced by the free-range chicken using a computer system automatically. This expert system uses the Certainty Factor method which aims to measure the level of certainty of facts or rules to describe an expert's belief in the problem at hand. This study shows how the process of calculating the Certainty Factor method in diagnosing free-range chicken disease with the initial combination rule to the last combination rule based on the selected symptoms, it can be concluded that the highest weight value is D01 Avian Influenza with a weight value of $0.99 \times 100 \%=99 \%$
\end{abstract}

Keywords- Certainty Factor, Expert System, Kampung Chicken

\begin{abstract}
Abstrak - Peternakan adalah kegiatan mengembangbiakkan dan pemeliharaan hewan ternak untuk mendapatkan manfaat dan hasil dari kegiatan tersebut. Kegiatan di bidang peternakan dapat dibagi atas dua golongan, yaitu peternakan hewan besar seperti sapi, kerbau dan kuda, sedangkan kelompok kedua yaitu peternakan hewan kecil seperti ayam, itik, burung dan lain-lain. Aktivitas peternakan ayam kampung telah ada sejak zaman dahulu. Ayam kampung dimulai dari generasi pertama yaitu dari keturunan ayam hutan merah (Gallus gallus). Beternak ayam kampung bukanlah hal yang mudah karena banyak yang harus diperhatikan dan pasti memiliki kedala, maka dari itu dibutuhkan Sistem pakar untuk membantu peternak dalam mendiagnosa dan mengetahui jenis penyakit beserta gejala yang dialami ayam kampung tersebut dengan menggunakan sistem komputer secara otomatis. Sistem pakar ini menggunakan metode Certainty Factor yang bertujuan untuk mengukur tingkat kepastian terhadap fakta atau aturan untuk menggambarkan keyakinan seorang pakar terhadap masalah yang sedang dihadapi. Dalam penelitian ini menunjukkan bagaimana proses perhitungan metode Certainty Factor dalam mendiagnosa penyakit ayam kampung dengan aturan kombinasi awal sampai aturan kombinasi terakhir berdasarkan gejala yang dipilih, maka dapat disimpulkan bahwa bobot nilai paling tinggi adalah D01 Flu Burung dengan nilai bobotnya $0,99 \times 100 \%=99 \%$
\end{abstract}

Kata kunci-Certainty Factor, Sistem Pakar, Ayam Kampung

\section{PENDAHULUAN}

Peternakan adalah kegiatan mengembang biakaan dan pemeliharaan hewan ternak untuk mendapatkan manfaat dan hasil dari kegiatan tersebtu[1].

Sistem peternakan diperkirakan telah ada sejak 9.000 SM yang dimulai dengan domestikasi anjing, kambing, dan domba. Ayam Kampung (Gallus domesticus) adalah jenis unggas ternak ras lokal yang banyak di pelihara oleh banyak orang dan dikenal dengan ayam buras atau ayam bukan ras sedangkan hidupnya berkeliaran di pekarangan. Namun beternak ayam kampung bukanlah hal yang mudah karena banyak yang harus diperhatikan dan pasti memiliki kendala[2]. Salah satu kendala beternak ayam kampung yang sering terjadi adalah rentannya terhadap serangan penyakit seperti: Penyakit Tetelo, Penyakit Cacing, Penyakit Berak Darah (Coccsidiosis) dan Penyakit Mata (Oxypilurasis)[3]. Untuk membantu dalam menangani permasalahan pada ayam kampung tersebut, maka dibutuhkan Sistem Pakar. Sistem pakar adalah kumpulan sistem yang membentuk perangkat lunak atau software dalam komputer yang dirancang untuk menggunakan fakta, teknik[4],[5]dan ilmu dalam pengambilan keputusan atas masalah yang biasanya hanya bisa diselesaikan oleh tenaga ahli atau pakar dalam bidangnya. Kemudian penggunaan metode Certainty Factor $(C F)$ agar pengguna dapat mengetahui derajat kepercayaan terhadap penyakit yang diderita[6],[7]. 


\section{METODE PENELITIAN}

\section{Analisa Masalah}

Analisa masalah ini dilakukan agar dapat memecahkan serta menyelesaikan masalah - masalah dalam menentukan jenis penyakit dan gejala yang diderita oleh ayam kampung tersebut.

\section{Pengumpulan Data}

Adapun teknik pengumpulan data yang peneliti gunakan adalah sebagai berikut[8],[9]:

a. Data primer merupakan data yang diambil/ diperoleh secara langsung dari sumber asli. Data jenis ini diperoleh dari hasil wawancara dengan pemilik ternak ayam kampung.

b. Data sekunder merupakan data pendukung yang sumbernya diperoleh dari dokter hewan.

\section{Analisis Data}

Analisis data ini dilakukan untuk memudahkan peneliti dalam mengolah data serta informasi dengan cara meriset secara mendalam terhadap para narasumber, yakni dimulai dengan melakukan wawancara secara langsung, melakukan pengumpulan data serta pendokumentasian.

\section{Penerapan Metode}

Setelah data dikumpulkan dan dianalisa, selanjutnya menerapkan metode Certainty Factor dan perhitungannya berdasarkan data yang telah diperoleh.

Metode yang akan digunakan dalam menentukan penyakit ayam pada penelitian ini adalah:

1. Memilih gejala penyakit.

2. Mencari penyakit berdasarkan gejala yang sudah dimasukkan.

3. Menghitung seluruh bobot yang ada pada masing masing gejala penyakit dengan menggunakan metode certainty factors (CFs).

4. Penyakit yang memiliki bobot tertinggi adalah kemungkinan penyakit yang diderita ayam.

\section{Perancangan Sistem}

Perancangan sistem merupakan tahapan yang menggambarkan rancang bangunan sistem yang dibuat. Pada tahapan ini juga merancang Interface dan juga merancang Database yang merupakan salah satu bagian yang paling penting dari merancang system. Perancangan sistem ini menggunakan UML yang terdiri dari perancangan Use Case Diagram, Activity Diagram, dan Class Diagram.

\section{Pengembangan Sistem}

Pada tahapan ini dilakukan metode pengembangan sistem guna untuk mengetahui kelengkapankelengkapan pada alur sistem. Pengembangan Sistem yang digunakan pada penelitian ini adalah model System Development Life Cycle (SDLC). Adapun jenisjenis dari System Development Life Cycle (SDLC) yaitu Metode waterfall, Metode Prototyping, Rapid Application Development (RAD), Metode Spiral dan lain sebagainya.

\section{Pengujian}

Tahapan ini berguna untuk menyesuaikan dan mencocokkan antara semua langkah pada penelitian. Pada tahapan ini dilakukan pemeriksaan agar sesuai antara data, hasil perhitungan metode dan sistem yang dibuat[10].

\section{Implementasi}

Setelah dilakukan pengembangan dan pengujian, tahap selanjutnya adalah implementasi. Pada tahapan ini dilakukan pembuatan sistem, program diterapkan sesuai dengan perancangan sistem dan desain yang dibuat dengan menggunakan Bahasa pemrograman PHP dan MYSQL sebagai database programnya.

\section{Analisa Data \\ III. HASIL DAN PEMBAHASAN}

Analisis data ini dilakukan untuk memudahkan peneliti dalam mengolah data serta informasi yang didapat dengan cara melakukan riset.

\section{a. Data Penyakit}

Jumlah penyakit yang diolah dalam sistem pakar penyakit pada ayam kampung ini ada 5 jenis penyakit. Jenis penyakit ini dapat dilihat pada tabel dibawah ini :

Tabel 1. Data Jenis Penyakit

\begin{tabular}{clc}
\hline $\begin{array}{c}\text { Kode } \\
\text { Penyakit }\end{array}$ & \multicolumn{1}{c}{ Nama Penyakit } & Bobot Keyakinan \\
\hline D01 & $\begin{array}{l}\text { Flu burung (AI=Avian } \\
\text { Influenza) }\end{array}$ & $96-100 \%$ \\
D02 & $\begin{array}{l}\text { Penyakit } \\
\text { (ND=Newcastle } \\
\text { Disease) }\end{array}$ & $86-95 \%$ \\
\hline D03 & Berak kapur (Pullorum) & $76-85 \%$ \\
\hline D04 & Gumboro & $66-75 \%$ \\
\hline D05 & Snot (Infeksius Coryza) & $60-65 \%$ \\
\hline
\end{tabular}

\section{b. Data gejala penyakit}

Data gejala penyakit yang digunakan dalam sistem pakar pada penyakit ayam kampung ini berjumlah 20 gejala. Adapun data gejala tersebut dapat dilihat pada tabel dibawah ini :

Tabel 2. Data gejala penyakit

\begin{tabular}{cl}
\hline KODE GEJALA & \multicolumn{1}{c}{ NAMA GEJALA } \\
\hline G001 & Ayam ngorok \\
\hline G002 & Ayam bersin-bersih \\
\hline G003 & sulit bernafas \\
\hline G004 & kurang nafsu makan \\
\hline G005 & jengger berwarna biru \\
\hline G006 & Sayap turun, keliatan kusam \\
\hline G007 & leher berputar kearah bawah \\
\hline G008 & Kotoran ayam berwarna putih \\
\hline G009 & Ayam keliatan ngantuk \\
\hline
\end{tabular}




\begin{tabular}{cl}
\hline \hline G0010 & gerakan lambat \\
\hline G0011 & bintik bintik merah pada kaki \\
\hline G0012 & Keluar cairan pada mata \\
\hline G0013 & Ayam batuk \\
\hline G0014 & Keluar cairan dari rongga mulut \\
\hline G0015 & Ayam mati mendadak \\
\hline G0016 & terjadi peradangan di sekitar dubur \\
\hline G0017 & Ayam menjadi lesu \\
\hline G0018 & Badan demam \\
\hline G0019 & keluar lendir dari hidung \\
\hline G0020 & mata bengkak serta berair \\
\hline
\end{tabular}

\section{c. Basis pengetahuan antara jenis dan gejala penyakit}

Dari pengetahuan yang didapat berupa jenis dan gejala penyakit pada ayam kampung, maka dapat dibuat basis pengetahuan berupa hubungan atau keterkaitanyang ada antara jenis dan gejala penyakit ayam kampung. Basis pengetahuandapat dilihat pada tabel dibawah ini :

Tabel 3. Hubungan antara jenis dan gejala penyakit pada ayam kampung

\begin{tabular}{|c|c|c|c|c|c|c|}
\hline \multirow{2}{*}{$\begin{array}{c}\text { Kode } \\
\text { Gejal } \\
\text { a }\end{array}$} & \multirow[b]{2}{*}{ Gejala } & \multicolumn{5}{|c|}{ Kode Jenis Penyakit } \\
\hline & & $\begin{array}{c}\text { D0 } \\
1\end{array}$ & $\begin{array}{c}\text { D0 } \\
2\end{array}$ & $\begin{array}{c}\text { D0 } \\
3 \\
\end{array}$ & $\begin{array}{c}\text { D0 } \\
4 \\
\end{array}$ & $\begin{array}{c}\text { D0 } \\
5 \\
\end{array}$ \\
\hline G001 & $\begin{array}{l}\text { Ayam } \\
\text { Ngorok }\end{array}$ & $\checkmark$ & & $\checkmark$ & & \\
\hline G002 & $\begin{array}{l}\text { Ayam } \\
\text { Bersin- } \\
\text { Bersih }\end{array}$ & $\checkmark$ & & $\checkmark$ & & \\
\hline G003 & $\begin{array}{l}\text { Sulit } \\
\text { Bernafas }\end{array}$ & $\checkmark$ & & $\checkmark$ & & $\checkmark$ \\
\hline G004 & $\begin{array}{l}\text { Kurang } \\
\text { Nafsu } \\
\text { Makan }\end{array}$ & $\checkmark$ & $\checkmark$ & & $\checkmark$ & \\
\hline G005 & $\begin{array}{l}\text { Jengger } \\
\text { Berwarna } \\
\text { Biru }\end{array}$ & $\checkmark$ & & $\checkmark$ & & \\
\hline G006 & $\begin{array}{l}\text { Sayap } \\
\text { Turun, } \\
\text { Keliatan } \\
\text { Kusam }\end{array}$ & $\checkmark$ & $\checkmark$ & & & \\
\hline G007 & $\begin{array}{l}\text { Leher } \\
\text { Berputar } \\
\text { Kearah } \\
\text { Bawah }\end{array}$ & $\checkmark$ & & & & \\
\hline G008 & $\begin{array}{l}\text { Kotoran } \\
\text { Ayam } \\
\text { Berwarna } \\
\text { Putih } \\
\end{array}$ & & $\checkmark$ & & $\checkmark$ & \\
\hline
\end{tabular}

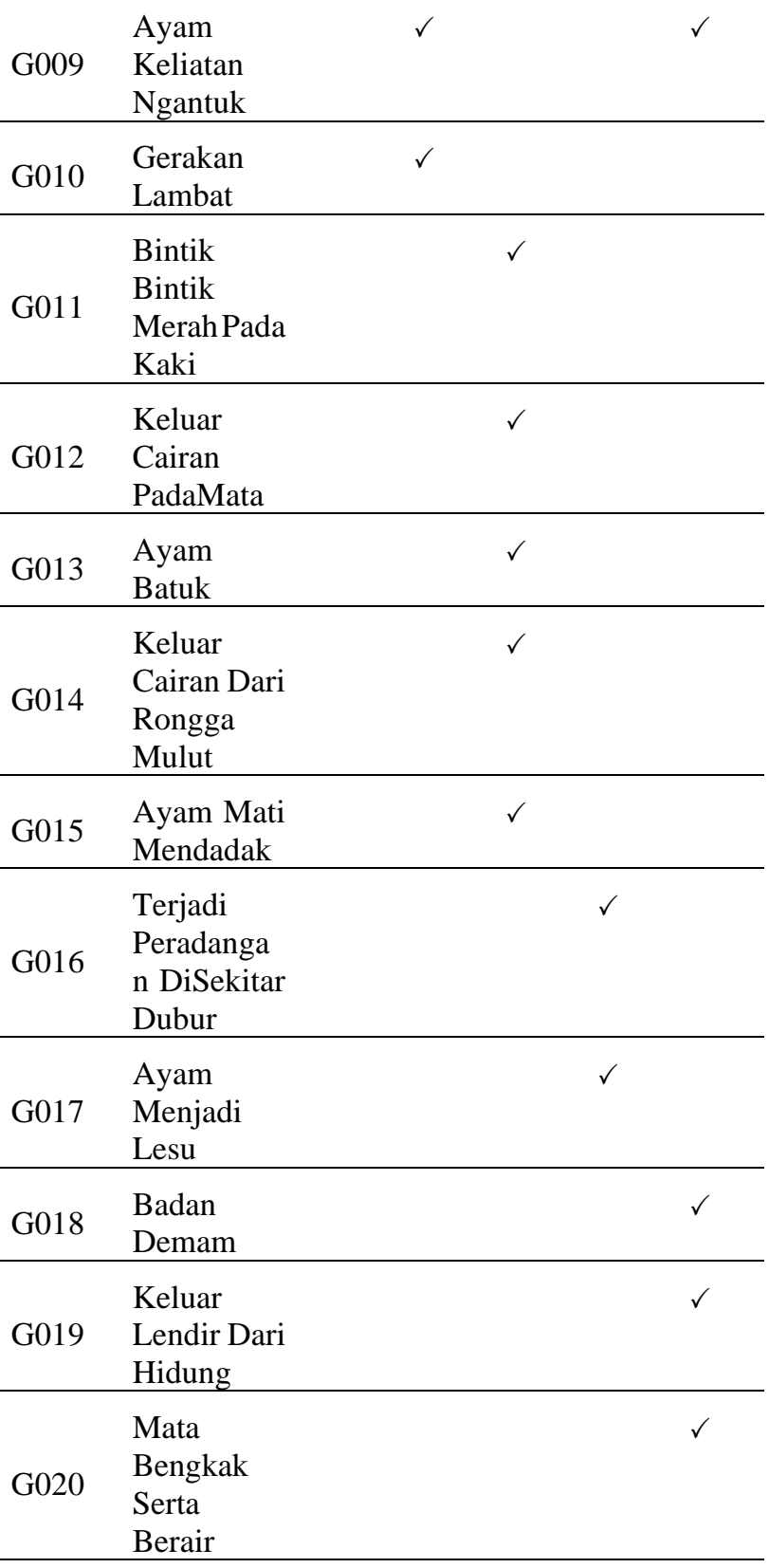

\section{d. Pembentukan Aturan (Rule)}

Adapun yang telah disajikan dalam aturan-aturan yang berbentuk pasangan keadaan aksi (condition-action) "JIKA (IF) keadaan terpenuhi atau terjadi MAKA (THEN)" adalah sebagai berikut:

\section{Tabel 4. Aksi-Kondisi}

\begin{tabular}{ll}
\hline Kode & \multicolumn{1}{c}{ Aturan } \\
\hline \multirow{3}{*}{ IF jengger kebiru-biruan } \\
& AND bintik-bintik merah pada kaki \\
& AND keluar cairan pada mata dan hidung \\
D01 & AND sulit bernafas \\
& AND batuk \\
& AND Bersin \\
& AND ngorok \\
\hline
\end{tabular}




\begin{tabular}{ll}
\hline \hline Kode & \multicolumn{1}{c}{ Aturan } \\
\hline & AND ayam mati mendadak \\
& THEN Flu burung (D01). \\
& \\
& IF ngorok \\
& AND bersin-bersin \\
D02 & AND sulit bernafas \\
& AND kurang nafsu makan \\
& AND jengger berwarna biru \\
& AND Sayap turun, keliatan kusam \\
& AND leher berputar kerarah bawah \\
& THEN Teleo (D02) . \\
& IF kotoran ayam berwarna putih \\
& AND ayam keliatan ngantuk \\
& AND Gerakan lambat \\
& AND sayap menggantung dan terlihat kusam \\
& AND nafsu makan berkurang \\
& THEN Berak kapur (D03). \\
& IF kurang nafsu makan \\
& AND ayam menjadi lesu \\
& AND terjadi peradangan disekitar dubur \\
AND kotoran berwarna putih serta berlendir \\
THEN Gumboro (D04) . \\
IF ayam ngantuk \\
AND susah bernafas \\
AND badan demam \\
AND keluar lendir dari hidung \\
AND mata bengkak serta berair \\
THEN Snot D05. \\
\hline
\end{tabular}

\section{A. Studi Kasus}

Setelah mendapatkan hasil jawaban dari beberapa pertanyaan yang diajukan, maka dilakukan perhitungan menggunakan metode certainty factor untuk tiap gejala.

Berikut adalah contoh kasus yang didapat di Puskeswan Lubuk Pakam yang akan dilakukan pengujiannya, seperti dibawah ini:

Peternak mengalami beberapa gejala penyakit pada ayam kampung miliknya kemudian pemilik ternak melakukan konsultasi ke dokter hewan, dari 20 pertanyaan yang diberikan kepada peternak maka didapat hasil jawaban seperti berikut:

Tabel 5. Hasil konsultasi peternak

\begin{tabular}{|c|c|c|}
\hline Kode & $\begin{array}{c}\text { Pertanyaan } \\
\text { berdasakan gejala }\end{array}$ & Jawaban \\
\hline G001 & Ayam Ngorok & Mungkin \\
\hline G002 & $\begin{array}{l}\text { Ayam Bersin- } \\
\text { Bersih }\end{array}$ & Mungkin \\
\hline G003 & Sulit Bernafas & Tidak \\
\hline G004 & $\begin{array}{l}\text { Kurang } \\
\text { Makan }\end{array}$ & Tidak \\
\hline G005 & Jengger Berwarna & Sedikit Yakin \\
\hline
\end{tabular}

\begin{tabular}{|c|c|c|}
\hline Kode & $\begin{array}{c}\text { Pertanyaan } \\
\text { berdasakan gejala }\end{array}$ & Jawaban \\
\hline & Biru & \\
\hline G006 & $\begin{array}{l}\text { Sayap Turun, } \\
\text { Keliatan Kusam }\end{array}$ & Sedikit Yakin \\
\hline G007 & $\begin{array}{l}\text { Leher Berputar } \\
\text { Kearah Bawah }\end{array}$ & Sedikit Yakin \\
\hline G008 & $\begin{array}{l}\text { Kotoran Ayam } \\
\text { Berwarna Putih }\end{array}$ & Yakin \\
\hline G009 & $\begin{array}{l}\text { Ayam Keliatan } \\
\text { Ngantuk }\end{array}$ & Mungkin \\
\hline G0010 & Gerakan Lambat & Mungkin \\
\hline G0011 & $\begin{array}{l}\text { Bintik Bintik } \\
\text { Merah Pada Kaki }\end{array}$ & Sedikit Yakin \\
\hline G0012 & $\begin{array}{l}\text { Keluar Cairan } \\
\text { Pada Mata }\end{array}$ & Mungkin \\
\hline G0013 & Ayam Batuk & Mungkin \\
\hline G0014 & $\begin{array}{lr}\text { Keluar } & \text { Cairan } \\
\text { Dari } & \text { Rongga } \\
\text { Mulut } & \end{array}$ & Sedikit Yakin \\
\hline G0015 & $\begin{array}{ll}\text { Ayam } & \text { Mati } \\
\text { Mendadak } & \end{array}$ & Yakin \\
\hline G0016 & $\begin{array}{l}\text { Terjadi } \\
\text { Peradangan Di } \\
\text { Sekitar Dubur }\end{array}$ & Sedikit Yakin \\
\hline G0017 & $\begin{array}{l}\text { Ayam Menjadi } \\
\text { Lesu }\end{array}$ & Mungkin \\
\hline G0018 & Badan Demam & Mungkin \\
\hline G0019 & $\begin{array}{l}\text { Keluar Lendir } \\
\text { Dari Hidung }\end{array}$ & Sedikit Yakin \\
\hline G0020 & $\begin{array}{l}\text { Mata Bengkak } \\
\text { Serta Berair }\end{array}$ & Sedikit Yakin \\
\hline
\end{tabular}

\section{B. Perhitungan Metode CF (Certainty Factor)}

Berdasakan studi kasus diatas, maka dapat dilakukan perhitungan menggunakan metode Certainty Factor untuk mengetahui penyakit apa yang dialami ayam kampung tersebut. Berikut cara perhitungannya: 
Tabel 6. Perhitungan menggunakan metode certainty factor

\begin{tabular}{|c|c|c|c|c|c|}
\hline $\begin{array}{l}\text { Ko } \\
\text { de }\end{array}$ & $\begin{array}{c}\text { Pertanyaa } \\
\text { n } \\
\text { berdasak } \\
\text { an gejala }\end{array}$ & $\begin{array}{c}\text { Jawaba } \\
\mathbf{n}\end{array}$ & $\begin{array}{c}\text { CF } \\
\text { (Paka } \\
\text { r) }\end{array}$ & $\begin{array}{l}\text { Cf } \\
(\mathbf{U} \\
\mathbf{s e} \\
\mathbf{r})\end{array}$ & $\begin{array}{c}\text { Cf } \\
\text { Co } \\
\text { mbi } \\
\text { nasi }\end{array}$ \\
\hline$\overline{\mathrm{G} 001}$ & $\begin{array}{l}\text { Ayam } \\
\text { Ngorok }\end{array}$ & $\begin{array}{l}\text { Mungki } \\
n\end{array}$ & 0.4 & $\begin{array}{l}0 . \\
4\end{array}$ & 0.16 \\
\hline$\overline{\mathrm{G} 002}$ & $\begin{array}{l}\text { Ayam } \\
\text { Bersin- } \\
\text { Bersih }\end{array}$ & $\begin{array}{l}\text { Mungki } \\
\mathrm{n}\end{array}$ & 0.4 & $\begin{array}{l}0 . \\
4\end{array}$ & 0.16 \\
\hline$\overline{\mathrm{G} 003}$ & $\begin{array}{l}\text { Sulit } \\
\text { Bernafas }\end{array}$ & Tidak & 0 & $\begin{array}{l}0 . \\
4\end{array}$ & 0 \\
\hline$\overline{\mathrm{G} 004}$ & $\begin{array}{l}\text { Kurang } \\
\text { Nafsu } \\
\text { Makan }\end{array}$ & Tidak & 0 & $\begin{array}{l}0 . \\
4\end{array}$ & 0 \\
\hline$\overline{\mathrm{G} 005}$ & $\begin{array}{l}\text { Jengger } \\
\text { Berwarna } \\
\text { Biru } \\
\end{array}$ & $\begin{array}{l}\text { Sedikit } \\
\text { yakin }\end{array}$ & 0.8 & $\begin{array}{l}0 . \\
8\end{array}$ & 0.64 \\
\hline G006 & $\begin{array}{l}\text { Sayap } \\
\text { Turun, } \\
\text { Keliatan } \\
\text { Kusam }\end{array}$ & $\begin{array}{l}\text { Sedikit } \\
\text { yakin }\end{array}$ & 0.8 & $\begin{array}{l}0 . \\
6\end{array}$ & 0.48 \\
\hline G007 & $\begin{array}{l}\text { Leher } \\
\text { Berputar } \\
\text { Kearah } \\
\text { Bawah }\end{array}$ & $\begin{array}{l}\text { Sedikit } \\
\text { yakin }\end{array}$ & 0.8 & 0.8 & 0.64 \\
\hline
\end{tabular}

\begin{tabular}{llllll}
\hline G008 & Kotora & & & & \\
& $\mathrm{n}$ & & & & \\
& Ayam & & & 0. & 0.8 \\
& Berwar & Yakin & 1 & 8 & \\
na & & & & \\
Putih & & & & \\
& & & & \\
& & & & & \\
& &
\end{tabular}

\begin{tabular}{|c|c|c|c|c|c|}
\hline G009 & $\begin{array}{l}\text { Ayam } \\
\text { Keliatan } \\
\text { Ngantuk }\end{array}$ & $\begin{array}{l}\text { Mungki } \\
\mathrm{n}\end{array}$ & 0.4 & $\begin{array}{l}0 . \\
2\end{array}$ & 0.08 \\
\hline$\overline{\mathrm{G} 010}$ & $\begin{array}{l}\text { Gerakan } \\
\text { Lambat }\end{array}$ & $\begin{array}{l}\text { Mungki } \\
\mathrm{n}\end{array}$ & 0.4 & $\begin{array}{l}0 . \\
4\end{array}$ & 0.16 \\
\hline G011 & $\begin{array}{l}\text { Bintik } \\
\text { Bintik } \\
\text { Merah } \\
\text { Pada Kaki }\end{array}$ & $\begin{array}{l}\text { Sedikit } \\
\text { yakin }\end{array}$ & 0.8 & 0.4 & 0.32 \\
\hline
\end{tabular}

\begin{tabular}{llllll}
\hline G012 & $\begin{array}{l}\text { Keluar } \\
\text { Cairan } \\
\text { Pada } \\
\text { Mata }\end{array}$ & $\begin{array}{l}\text { Sedikit } \\
\text { yakin }\end{array}$ & 0.8 & $\begin{array}{l}0 . \\
6\end{array}$ & 0.48 \\
G013 & $\begin{array}{l}\text { Ayam } \\
\text { Batuk }\end{array}$ & $\begin{array}{l}\text { Mungki } \\
\text { n }\end{array}$ & 0.4 & $\begin{array}{l}\text { 0. } \\
\text { G014 }\end{array}$ & 0.16 \\
\hline & $\begin{array}{l}\text { Keluar } \\
\text { Cairan } \\
\text { Dari } \\
\text { Rongga } \\
\text { Mulut }\end{array}$ & Sedikit & 0.8 & 0. & 0.48 \\
& yakin & & 6 & \\
\hline
\end{tabular}

\begin{tabular}{|c|c|c|c|c|c|}
\hline \multicolumn{2}{|c|}{$M D\left[h, e 1^{\wedge} e 2\right]=$} & \multicolumn{4}{|c|}{$\begin{array}{c}0 M B\left[h, e 1^{\wedge} e 2\right]=1 \\
M D[h, e 1]+M D[h, e 2] .(1-M D[h, e\end{array}$} \\
\hline G015 & $\begin{array}{l}\text { Ayam } \\
\text { Mati } \\
\text { Mendadak }\end{array}$ & Yakin & 1 & $\begin{array}{l}0 . \\
8\end{array}$ & 0.8 \\
\hline G016 & $\begin{array}{l}\text { Terjadi } \\
\text { Peradanga } \\
\text { n Di } \\
\text { Sekitar } \\
\text { Dubur }\end{array}$ & $\begin{array}{l}\text { Sedikit } \\
\text { yakin }\end{array}$ & 0.8 & $\begin{array}{l}0 . \\
8\end{array}$ & 0.56 \\
\hline G017 & $\begin{array}{l}\text { Ayam } \\
\text { Menjadi } \\
\text { Lesu }\end{array}$ & $\begin{array}{l}\text { Mungki } \\
\mathrm{n}\end{array}$ & 0.4 & $\begin{array}{l}0 . \\
6\end{array}$ & 0.24 \\
\hline G018 & $\begin{array}{l}\text { Badan } \\
\text { Demam }\end{array}$ & $\begin{array}{l}\text { Mungki } \\
\mathrm{n}\end{array}$ & 0.4 & $\begin{array}{l}0 . \\
4\end{array}$ & 0.16 \\
\hline G019 & $\begin{array}{l}\text { Keluar } \\
\text { Lendir } \\
\text { Dari } \\
\text { Hidung }\end{array}$ & $\begin{array}{l}\text { Sedikit } \\
\text { yakin }\end{array}$ & 0.8 & $\begin{array}{l}0 . \\
4\end{array}$ & 0.32 \\
\hline G020 & $\begin{array}{l}\text { Mata } \\
\text { Bengkak } \\
\text { Serta } \\
\text { Berair }\end{array}$ & $\begin{array}{l}\text { Sedikit } \\
\text { yakin }\end{array}$ & 0.8 & $\begin{array}{l}0 . \\
8\end{array}$ & 0.64 \\
\hline
\end{tabular}

\section{Penyelesaian :}

$$
\begin{aligned}
M B\left[h, e 1^{\wedge} e 2=\right. & \left\{\begin{array}{c}
0 M D\left[h, e^{\wedge} e 2\right]=1 \\
M B[h, e 1]+M B[h, e 2] .(1-M B[h, e 1])
\end{array}\right. \\
& =0.16+0.16 *(1-0.16) \\
& =0.16+0.16 *(0.84) \\
& =0.16+0.1344
\end{aligned}
$$

CFOld $1=0.2944$

$$
\begin{aligned}
& =0.2944+0 *(1-0.2944) \\
& =0.2944+0 *(0.7056) \\
& =0.2944+0 \\
\text { CFOld } 2 \quad & 0.2944
\end{aligned}
$$

$$
\begin{aligned}
M B\left[h, e 1^{\wedge} e 2=\right. & \begin{array}{c}
0 M D\left[h, e^{\wedge} e 2\right]=1 \\
M B[h, e 1]+M B[h, e 2] .(1-M B[h, e 1])
\end{array} \\
& =0.2944+0 *(1-0.2944) \\
& =0.2944+0 *(0.7056) \\
& =0.2944+0
\end{aligned}
$$

CFOld $3=0.2944$

$$
\begin{aligned}
M D[h, e 1 \wedge e 2]= & \left\{\begin{array}{c}
0 M B\left[h, e 1^{\wedge} e 2\right]=1 \\
M D[h, e 1]+M D[h, e 2] \cdot(1-M D[h, e 1])
\end{array}\right. \\
& =0.2944+0.64 *(1-0.2944) \\
& =0.2944+0.64 *(0.7056) \\
& =0.2944+0.451584
\end{aligned}
$$

CFOld $4=0.745984$

$$
\begin{aligned}
M D[h, e 1 \wedge e 2]= & \left\{\begin{array}{c}
0 M B\left[h, e 1^{\wedge} e 2\right]=1 \\
M D[h, e 1]+M D[h, e 2] .(1-M D[h, e 1])
\end{array}\right. \\
& =0.745984+0.48 *(1-0.745984)
\end{aligned}
$$




$$
\begin{aligned}
& =0.745984+0.48 *(0.254016) \\
& =0.745984+0.12192768 \\
& \text { CFOld } 5=0.86791168 \\
& \begin{aligned}
M D\left[h, e 1^{\wedge} e 2\right]=\left\{\begin{array}{c}
0 M B\left[h, e 1^{\wedge} e 2\right]=1 \\
M D[h, e 1]+M D[h, e 2] \cdot(1-M D[h, e 1])
\end{array}\right. \\
=0.86791168+0.64 *(1-0.86791168) \\
=0.86791168+0.64 *(0.13208832) \\
=0.86791168+0.0845365248
\end{aligned} \\
& \text { CFOld } 6=0.9524482048
\end{aligned}
$$

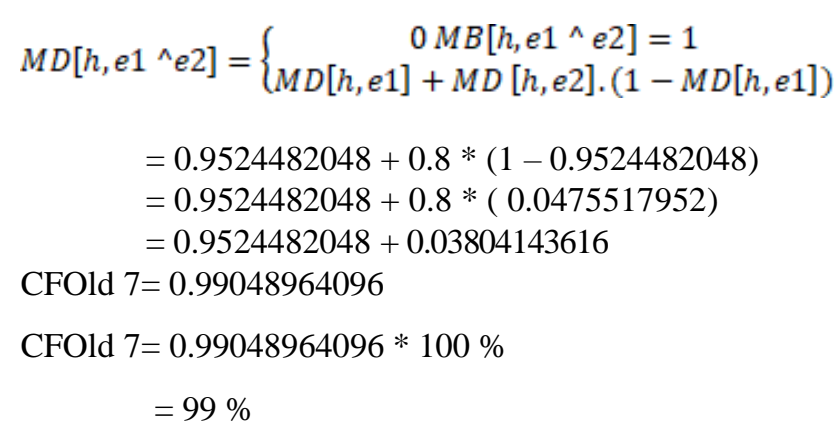

Perhitungan berakhir di CFOld 7 dikarenakan hasil akhir tidak terhingga sehingga dapat diambil kesimpulan dari perhitungan metode certainty factor ini mendapatkan presentasi nilai sebesar 99\%. Maka Berdasarkan tabel 4.9 diatas penyakit tersebut adalah Penyakit Flu Burung (AI=AvianInfluenza) karena persentase nilai berada pada range $96 \%-100 \%$.

\section{KESIMPULAN}

Kesimpulan yang didapat dari pembangunan perangkat lunak Sistem Pakar mendiagnosa penyakit ayam kampung menggunakan metode Certainty Factor adalah sebagai berikut:

1. Dengan adanya data-data yang lengkap, maka sangat mendukung penulis dalam pembuatan aplikasi sistem pakar ini.

2. Setelah dilakukannya pengujian dengan menggunakan metode certainty factor, maka didapatlah nilai kepastian sehingga dapat membantu peternak dalam mengambil keputusan yang akurat dan efektif.

3. Dengan dibangunnya sistem pakar berbasis web ini, maka dapat membantu peternak untuk mendapatkan informasi tentang gejala dan jenis penyakit pada ayam kampung dengan cepat.

\section{REFERENSI}

[1] R. Oktapiani, "Sistem Pakarmendeteksi Permasalahan Komputer Dari Beep Bios Dengan Metode Forward Chaining," Jurnal Tekno Insentif, vol. 11, no. Ci, pp. 43-52, 2017, doi: 10.1016/B978-1-907568-46-6/00015-X.
F. A. Sianturi, "Implementasi Metode Certainty Factor Untuk Diagnosa Kerusakan Komputer," MEANS (Media Informasi Analisa dan Sistem), vol. 4, no. 2, pp. 176-184, 2019.

[3] S. Ilyas and S. R. Yulianti, Ilmu Penyakit Mata. 2017.

[4] I. P. Kusumawijaya, "Aplikasi Sistem Pakar Kerusakan Personal Computer Menggunakan Metode Certainty Factor," ICIT Journal, vol. 6, no. 2, pp. 183-194, 2020, doi: 10.33050/icit.v6i2.1115.

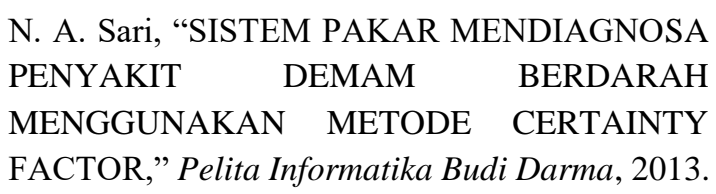

D. Kiray and F. A. Sianturi, "Diagnose Expert System Computer Malfunction Certainty Factor Method," Journal Of Computer Networks, Architecture and High Performance Computing, 2020, doi: 10.47709/cnapc.v2i1.358.

[7] K. E. Setyaputri and A. Fadlil, "Analisis Metode Certainty Factor pada Sistem Pakar Diagnosa Penyakit THT," Jurnal Teknik Elektro, vol. 10, no. 1, pp. 30-35, 2018.

[8] T. Hidayat, H. N. Nasution, S. W. R. Nasution, and R. Fauzi, "SISTEM PAKAR UNTUK MENDIAGNOSA PENYAKIT LUPUS DENGAN MENGGUNAKAN METODE CERTAINTY FACTOR," JURNAL EDUCATION AND DEVELOPMENT, 2019, doi: 10.37081/ed.v7i3.1201.

[9] T. Hidayat, H. N. Nasution, S. W. R. Nasution, and R. Fauzi, "Sistem Pakar Untuk Mendiagnosa Penyakit Lupus Dengan Menggunakan Metode Certainty Factor," Jurnal Education and Development, vol. 7, no. 3, p. 114, 2019, doi: 10.37081/ed.v7i3.1201.

[10] E. P. Gunawan and R. Wardoyo, "An Expert System Using Certainty Factor for Determining Insomnia Acupoint," IJCCS (Indonesian Journal of Computing and Cybernetics Systems), vol. 12, no. 2, p. 119, 2018, doi: 10.22146/ijccs.26328. 